\title{
Chronic Hemolysis
}

National Cancer Institute

\section{Source}

National Cancer Institute. Chronic Hemolysis. NCI Thesaurus. Code C153064.

Persisting and longstanding disruption of erythrocyte membrane integ rity and the resulting release of hemoglobin. 